https://doi.org/10.52449/1857-4114.2020.36-2.09

CZU: 796.093: $311+796.325$

\title{
THE METHODOLOGY OF APPLYING THE "DATA VOLLEY" PROGRAMME OF STATISTICAL ANALYSIS WITHIN VOLLEYBALL SPORTS COMPETITIONS
}

\author{
Harabagiu Neculai ${ }^{1}$, ORCID: 0000-0002-9806-4170 \\ 1"Dunarea de Jos" University, Galati, Romania
}

\begin{abstract}
In volleyball as in other sports games, the statistical analysis of the competition is considered to be an important means of diagnosing performance in order to determine parameters for targeting the training process, ideas and strategies during competitions.

In recent years, the volleyball game has become more and more dynamic, being characterized by the variety of game phases and the speed at which they alternate during competitions. As a result, the game has become increasingly difficult to follow, without having available new technological methods to help the coach track the multitude of game actions for each player or the entire team. At the international level, there are several performance evaluation methodologies, but in Romania, at senior level there are not many such methods of analysis and evaluation that give us complete and objective statistics on performance. At the moment, a very effective methodology from our point of view, which can be applied in the practice of volleyball, is the 'Data Volley' statistical analysis. This program of evaluating performance is a very complex one and offers us many opportunities. Thus, in this paper, we propose the application of this statistical analysis software in the official competitions of the volleyball game, at senior level.
\end{abstract}

Keywords: volleyball, seniors, methodology, Data Volley, sports competitions.

According to specialists in the field of men's volleyball, the level of the game has increased significantly with such a dynamic and a speed of execution of the technical elements, that it is very difficult to track each player's action of the game or even the entire team $[3,5,6]$.

To solve all these problems and draw certain conclusions about the efficiency of players in the game, related to data processing during the competition or during training lessons, coaches need to invest a lot of time and put in a lot of hard work.

All this makes the specialists $[4,5,7]$ constantly looking for the new methodology to assess each player's game actions, and then be able to process them operationally and come up with some solutions to increase their game efficiency. To this end, a statistical analysis and assessment programme was developed, provided by Data Project for professional federations and clubs, under the name of Data Volley. This software was designed strictly for volleyball and it supports all coaches who want to maximize the efficiency in the game of the teams they work for.

Further on we have a detailed description of how Data Volley is applied in the statistical and video assessment of players. The principle of evaluating players through statistical analysis represents a structured model to describe the game so as to become a valid and meaningful support in the team and game decision-making. The advantages of using such a program are: abstractization, low cost, speed of real-time data, but also objectivity of player selection.

The new version of Data Volley software is used internationally, and this guarantees a simple, fast and user-accessible approach to 
player selection through statistical data. It can be used by specialized people (statisticians), but also by non-specialized people.

The Data Volley statistical analysis software consists of two main parts:

evaluation of players;

analysis of the data.

Analysing the statistical data provided by Data Volley, it can be used as follows:

$>$ during matches, being of real help in decision-making, but also in verifying the game plan previously established;

before the match, for its tactical preparation (individually and collectively analysing the actions of the opponents, discovering their weaknesses, the distribution of the Lifter, the directions of attack, etc.);

during training, it can be used to improve certain weaker rotations and increase efficiency in the game by optimizing the technical-tactical elements.

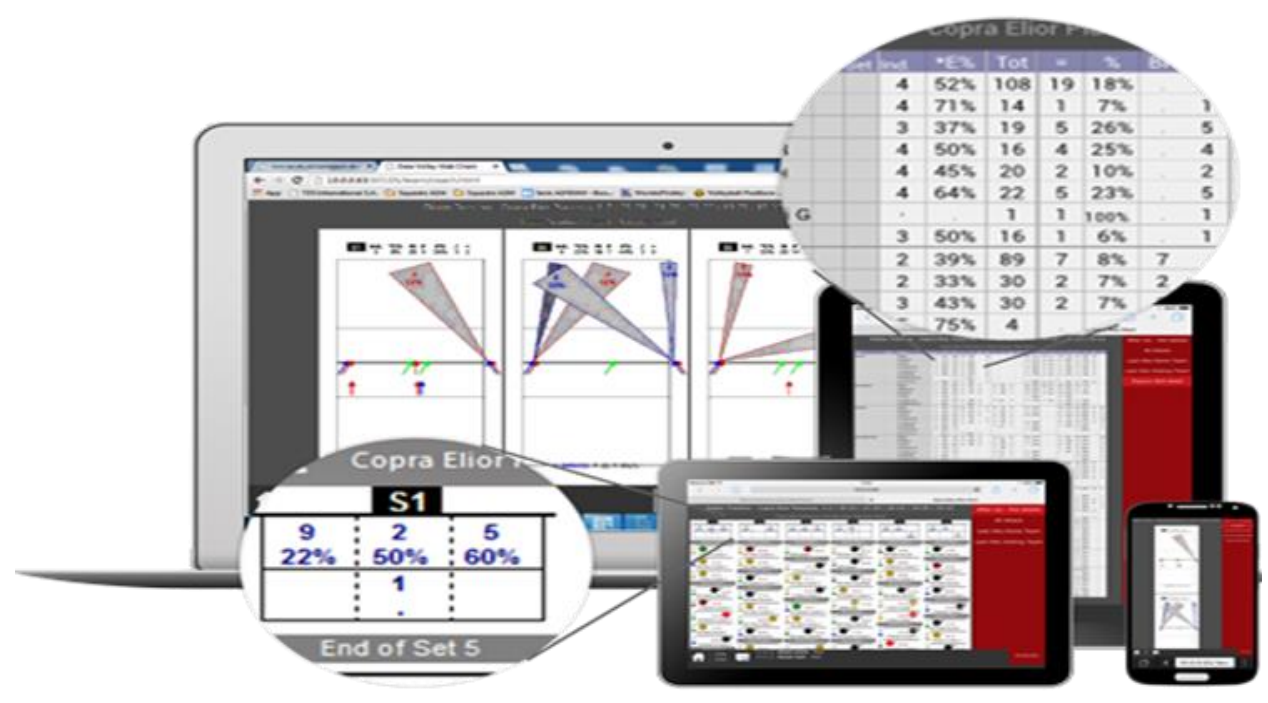

Photo 1. Statistical analysis and functions provided by the "Data Volley" software [9]

The program has one of the fastest computer data recording systems and gives us countless opportunities. Being a program of recording, assessment and analysis of game actions, the data provided by the program allow us to transform what we see (each game action), through standard codes that are subsequently analysed by the computer and give us details of the abilities of a single player, of the entire team, at a certain time of the game, on a certain position in the field, on a single set or on all sets in an entire season. Thus, each technical process used in the volleyball game is represented by a code, defined by a letter on the keyboard. For e.g.: $S$ - service, R - takeover, A - attack, etc. (Table $1)$. 
Table 1. Codes of each technical process [1]

\begin{tabular}{|c|c|}
\hline \multicolumn{2}{|c|}{ Game actions } \\
\hline S & Service \\
\hline R & Reception \\
\hline A & Attack \\
\hline B & Blocking \\
\hline D & Defence \\
\hline E & Passing \\
\hline F & Free ball \\
\hline
\end{tabular}

In turn, the technical processes have a certain efficiency (quality), which is why the software provides a number of codes represented by various characters: for e.g. "\#" indicates an ace service, a successful attack, an excellent reception, etc., whereas $"="$ represents a wrong action, (Table 2, 3, 4, 5). There can be analysed a number of 7 technical processes, which can be described by the 6 different characters shown below, for a detailed analysis of each technical element.

Table 2. Evaluation of the service by the Data Volley software [1]

\begin{tabular}{|c|c|}
\hline \multicolumn{2}{|r|}{ Serve } \\
\hline$=$ & Error - service in net, service out, foot fault. \\
\hline 1 & Half a point won by one's own team - the opposing team's reception is over the net. \\
\hline- & Negative - the opponent does a perfect reception and has all the versions of attack. \\
\hline$!$ & Good - the opponent cannot use any combination (e.g. reception in the 3-meter area). \\
\hline+ & Positive - the opponent has only one attack option. \\
\hline \# & Ace - direct point. \\
\hline
\end{tabular}

Table 3. Evaluation of the reception by the Data Volley software [1]

\begin{tabular}{|c|c|}
\hline \multicolumn{2}{|r|}{ Reception } \\
\hline$=$ & Error - direct point for the opponent. \\
\hline / & Poor - the ball goes into the opposing court - half a point won by the opposing team. \\
\hline- & Negative - one attack option. \\
\hline$!$ & Ball took over after the 3-meter line - few options of attack. \\
\hline+ & $\begin{array}{l}\text { Positive - the reception reaches the } 3 \text {-m line area, the lifter has several options of attack, } \\
\text { but cannot use all combinations. }\end{array}$ \\
\hline \# & Perfect reception - the lifter can use all the options in attack. \\
\hline
\end{tabular}

Table 4. Evaluation of the attack by the Data Volley software [1]

\begin{tabular}{|c|c|}
\hline \multicolumn{2}{|r|}{ Attack } \\
\hline$=$ & Fault - attack off the field or in the net. \\
\hline I & Blocked attack - the point goes to the opponent. \\
\hline- & Weak - easily recovered by the opponent, who can play the ball again. \\
\hline ! & Blocked, but recovered by the team that carried out the attack. \\
\hline+ & Positive - the opponent hardly defends itself, the team carrying out the attack still has a chance. \\
\hline \# & Direct point. \\
\hline
\end{tabular}


Table 5. Evaluation of the blocking by the Data Volley software [1]

\begin{tabular}{|c|c|}
\hline \multicolumn{2}{|r|}{ Blockage } \\
\hline$=$ & Error - block out, the blocking hits the net. \\
\hline / & Block out - the point goes to the opposing team. \\
\hline- & Poor - the opponent can recover and play the ball again. \\
\hline+ & $\begin{array}{l}\text { Positive - the ball is touched during the blocking and can be played again by one's own } \\
\text { team. }\end{array}$ \\
\hline \# & Direct point. \\
\hline
\end{tabular}

Table 6 shows the assessment system of the efficiency, also used by the Italian national team, for each game action and which we also used in our research. For example, to find out the efficiency at service, reception and defence, one calculates the sum of the percentages of positive actions, whereas for attack, blocking, passes and free balls received from the opponent, one calculates the difference between the percentage of positive and negative actions.

Table 6. The calculus formula of efficiency for each game action [1]

\begin{tabular}{|c|c|}
\hline Basics & $\frac{\text { Calculus formula of }}{\text { efficiency }}$ \\
\hline Serve & $(\% \#)+(\% /)+(\%+)+(\% !)$ \\
\hline Reception & $(\% \#)+(\%+)$ \\
\hline Attack & $(\% \#)-(\% /)-(\%=)$ \\
\hline Block & $(\% \#+(\%+)-(\% /)-(\%=)$ \\
\hline Dig-Defence & $(\% \#)+(\% /)+(\%+)$ \\
\hline Set & $(\% \#)+(\%+)-(\% /)-(\%=)$ \\
\hline Free ball & $(\% \#)+(\%+)-(\% /)-(\%=)$ \\
\hline
\end{tabular}

Once the codes are entered, the program will handle the rest of the calculations. A large number of pre-set functions will help decipher the opponents' tactical schemes, highlighting their strengths and weaknesses. Analysing only the basic codes, you can obtain important details about the abilities of a single player, of the whole team, at a certain point in the game, on a certain position on court, for a single set, for a single match or for all the matches in an entire season. Of course, detailed analyses can be made on each rotation, on each separate technical element, at a certain point in the set or match. Thus, with this software we can select exactly the parameters that we want to analyse.
Date Volley 2007 has the ability to provide statistical details by: team, player or a detailed analysis for all players. Here we can obtain information on each technical element separately, on each rotation or an analysis on a single set or sets. The difference between the three analyses is the order in which the information can be shown. The choice between one or the other depends on the type of information you want to get in the statistical tables. For example, player analysis can be used at any time to evaluate the performance of one or more players when applying different abilities or rotations (or both). Analysis on the desired technical element can be used at any time to see the evolution of 
players compared to other players. Rotation analysis is used when the coach wants to know the effectiveness of a technical element according to rotation.

Here are some examples of table analysis to differentiate the analyses:

- the analysis of technical actions: details of the actions of the game, per individual and per team (Photo 2),

- the player analysis: on a single technical process (Photo 3),
- analysis on each rotation: service details in all 6 rotations (Photo 4 ).

In the table below (Photo 2), we have a statistical example of the technical elements of the game, they appear in the first column, and the details of each player appear in the second column. This kind of statistic is helpful when the coach wants to compare the individual performance of each player on each technical element. You can always increase or reduce the statistical specificity by entering one or more codes (filters).

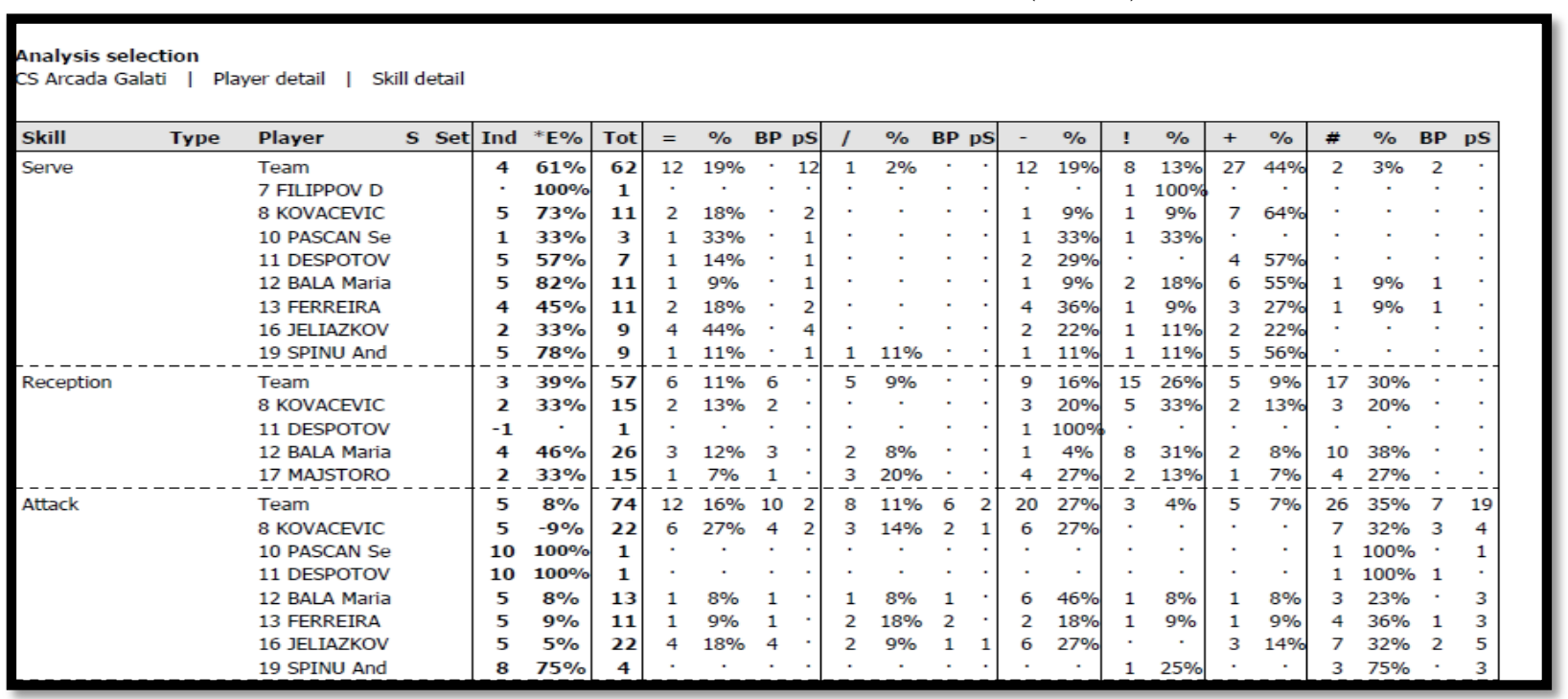

Photo 2. Graphic representation of the results of the technical elements of the game

Another way to evaluate statistically is to select the players or player you want to analyse on a single technical process. In the figure below we have an example of analysis of a single technical element of the game (the attack), for all the players who performed this action and at team level (Photo 3).

Iotal Analysis by Player

Cs Arcada Galati | Player detail | Atk after Rec | OR $\left[{ }^{*} \#, 1\right]\left[{ }^{*} R+, 1\right]$

\begin{tabular}{|c|c|c|c|c|c|c|c|c|c|c|c|c|c|c|c|c|c|c|c|c|c|c|c|c|}
\hline Player & Skill & Type & S Set & Ind & "E\% & Tot & $=$ & $\%$ & BP & ps & I & $\%$ & BP & ps & - & $\%$ & $!$ & $\%$ & + & $\%$ & $\#$ & $\%$ & & $\mathrm{pS}$ \\
\hline Team & Atk after Rec & & & 8 & $53 \%$ & 344 & 15 & $4 \%$ & 15 & . & 22 & $6 \%$ & . & . & 58 & $17 \%$ & . & . & 30 & $9 \%$ & 219 & $64 \%$ & .2 & 219 \\
\hline 2 IVAN R. & & & & 7 & $42 \%$ & 73 & 3 & $4 \%$ & 3 & . & 4 & $5 \%$ & . & . & 17 & $23 \%$ & . & . & 11 & $15 \%$ & 38 & $52 \%$ & . & 38 \\
\hline 5 волІс м. & & & & 8 & $58 \%$ & 50 & 4 & $8 \%$ & 4 & . & 3 & $6 \%$ & . & . & 6 & $12 \%$ & . & . & 1 & $2 \%$ & 36 & $72 \%$ & . & 36 \\
\hline 6 BISSETTE J. & & & & 8 & $69 \%$ & 68 & 1 & $1 \%$ & 1 & . & 3 & $4 \%$ & . & . & 10 & $15 \%$ & . & . & 3 & $4 \%$ & 51 & $75 \%$ & . & 51 \\
\hline 7 PEREZ A. & & & & 5 & . & 1 & . & . & . & . & . & . & . & . & . & . & . & . & 1 & $100 \%$ & . & . & . & . \\
\hline 11 CUCIUREA & & & & 7 & $36 \%$ & 14 & . & . & . & . & 1 & $7 \%$ & . & . & 7 & $50 \%$ & . & . & . & . & 6 & $43 \%$ & . & 6 \\
\hline 12 TERZIC M. & & & & 7 & $35 \%$ & 26 & 2 & $8 \%$ & 2 & .1 & 2 & $8 \%$ & . & .1 & 4 & $15 \%$ & . & . & 5 & $19 \%$ & 13 & $50 \%$ & . & 13 \\
\hline
\end{tabular}

Photo 3. Graphic representation of the effectiveness of the attack 
In the table below (Photo 4), it can be seen that we can analyse each technical element of the team's game on each rotation, which can help the coach to identify very quickly in which rotation the team is not effective (for example in rotation 4 we have an efficiency of
$33 \%$ ) and can intervene with relevant solutions, improvements or corrections. Such a table can be modified at any time depending on the information you want to obtain at the time by changing the necessary parameters.

\begin{tabular}{|c|c|c|c|c|c|c|c|c|c|c|c|c|c|c|c|c|c|c|c|c|c|c|}
\hline \multicolumn{23}{|c|}{$\begin{array}{l}\text { Analysis selection } \\
\text { CS Arcada Galati | Player detail }\end{array}$} \\
\hline Type & Player & $\mathbf{S}$ & Set & Ind & ${ }^{*} E \%$ & Tot & $=$ & $\%$ & BP pS & 1 & $\%$ & BP pS & - & $\%$ & ! & $\%$ & + & $\%$ & $\#$ & $\%$ & BP & pS \\
\hline \multirow[t]{6}{*}{ Serve } & Team & 1 & & 4 & $62 \%$ & 8 & 1 & $12 \%$ & 1 & $\cdot$ & $\cdot$ & $\cdot$ & 2 & $25 \%$ & 1 & $12 \%$ & 4 & $50 \%$ & $\cdot$ & $\cdot$ & $\cdot$ & . \\
\hline & & 6 & & 5 & $73 \%$ & 11 & 2 & $18 \%$ & - 2 & · & · & · & 1 & $9 \%$ & 1 & $9 \%$ & 7 & $64 \%$ & $\cdot$ & . & . & . \\
\hline & & 5 & & 4 & $45 \%$ & 11 & 2 & $18 \%$ & - 2 & . & · & · & 4 & $36 \%$ & 1 & $9 \%$ & 3 & $27 \%$ & 1 & $9 \%$ & 1 & . \\
\hline & & 4 & & 2 & $33 \%$ & 9 & 4 & $44 \%$ & 4 & · & . & $\cdot$ & 2 & $22 \%$ & 1 & $11 \%$ & 2 & $22 \%$ & $\cdot$ & $\cdot$ & · & $\cdot$ \\
\hline & & 3 & & 4 & $71 \%$ & 14 & 2 & $14 \%$ & $\cdot \quad 2$ & . & $\cdot$ & · & 2 & $14 \%$ & 3 & $21 \%$ & 6 & $43 \%$ & 1 & $7 \%$ & 1 & . \\
\hline & & 2 & & 5 & $78 \%$ & 9 & 1 & $11 \%$ & 1 & 1 & $11 \%$ & $\cdot$ & 1 & $11 \%$ & 1 & $11 \%$ & 5 & $56 \%$ & $\cdot$ & $\cdot$ & $\cdot$ & $\cdot$ \\
\hline
\end{tabular}

Photo 4. Graphic representation of service efficiency during each rotation

Among the most used functions we list the Zone Chart function which allows the assessment of abilities according to the area of the field in which they were executed, the player who was in action, for each rotation and with the percentage of efficiency on each rotation, which helps to study the area where the best or worst results were obtained (Photo $5)$.

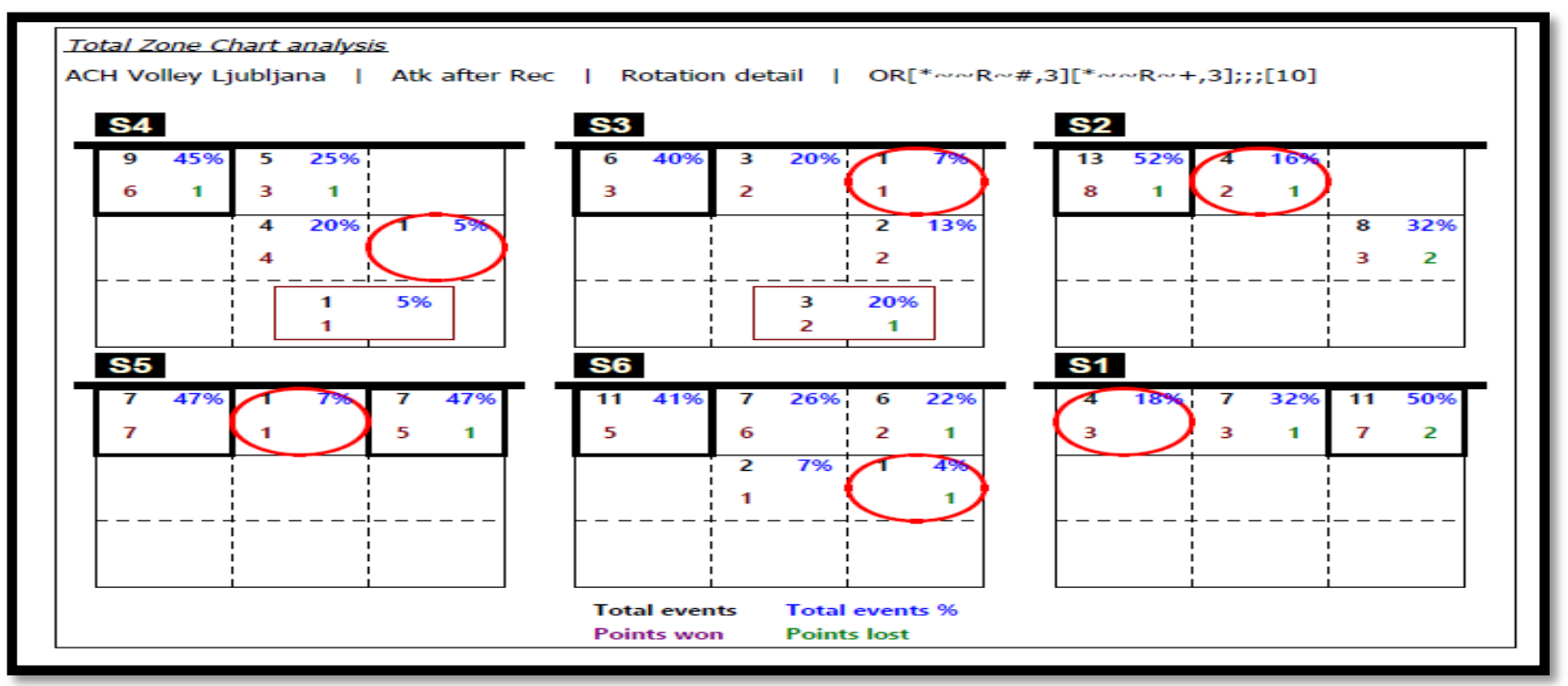

Photo 5. Graphic representation of actions in attack, for each rotation

This example shows us information about the team's attacks:

- the total number of strikes carried out in each area;

- the percentage of strikes carried out in that area;

- points lost in that area;
- points earned in that area.

Another important feature used by coaches is the Directions Chart, which highlights the area from which the player performs the attack shot and his preferred direction (Photo 6). For example, if the coach wants to know what the attacking directions or 
attack preferences of a player are, he can opt for this function and will be able to learn the player's predilections. In conclusion, we can find out the area and direction where it was most effective, the area where it has the most errors, their number and percentage.

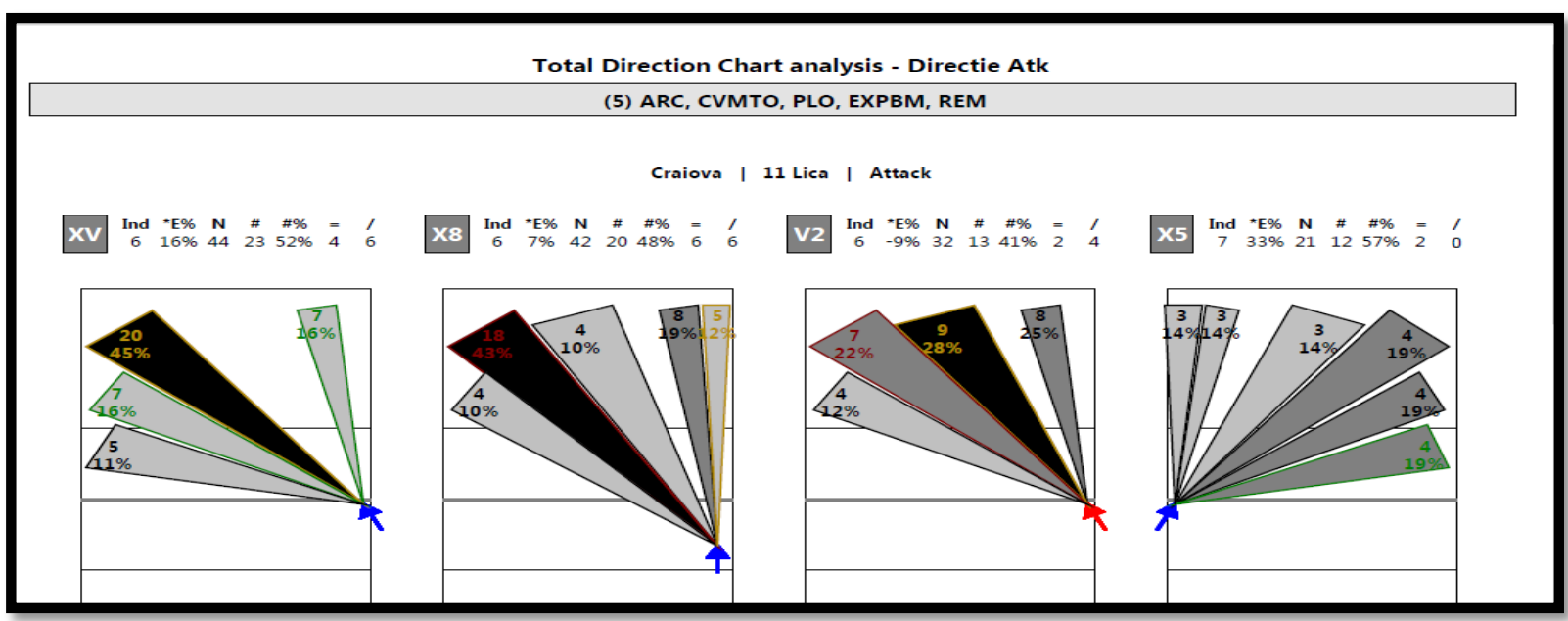

Photo. 6. Graphic representation of attack directions

Perhaps the most important and at the same time used function of this software, by coaches, is the distribution of the Setter (Setter calls). This allows the trainer to make out a configuration of the Lifter preferences in the construction phase. The analysis itself helps to study the position of the opponent Setter and highlights the favourite areas in the attack phase, taking into account the rotation, the quality of the reception and the area where the middle blocker is called for the combination.
All these pieces of information can make it easier for the coach to develop a tactical strategy against any opponent.

In the chart below (Photo. 7), the total distribution of the Lifter passes can be observed, the area in which the Middle blocker player is called (marked with blue arrows) or depending on the area where the takeover from service is carried out, the markings in grey indicating this.

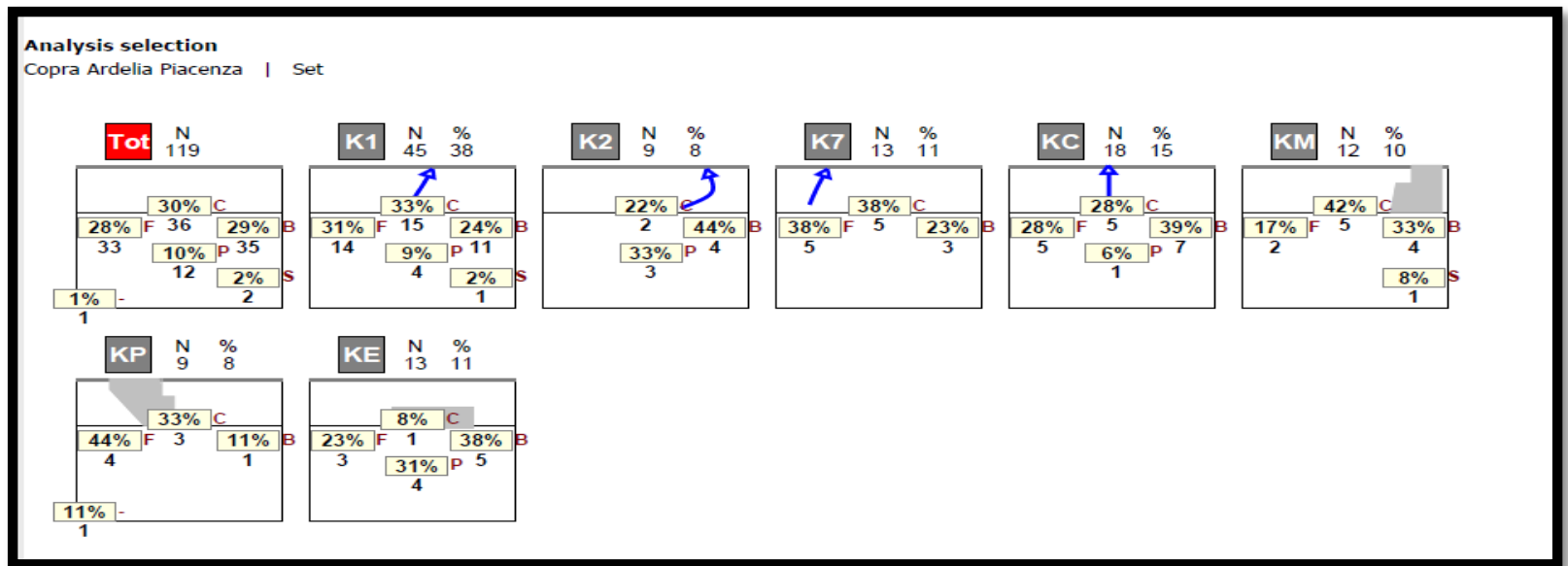

Photo 7. Graphical representation of the Setter distribution (Setter call) 
In addition to the variety of statistical analyses offered, the Data Volley also includes a system of analysis and video evaluation, under the name of Data Video. This system was designed to be easy to use, to provide flexibility in as short a time as possible. It can be used in all team or individual sports, where the players want to improve their sports performance technically and tactically and was designed to make it easier for coaches to analyse their own team's game, as well as that of their opponents.

With the help of this system [2], we can make video montages of the actions of each player or the entire team, depending on the requirements of the coach. Thus, The Data Video system can help to:

$>$ a thorough analysis of the video, so that it can subsequently be used to intervene in the correction of the technical and tactical elements of the players;

$>$ analysis of opponents, in order to draw up an objective game plan;

$>$ creating montages with relevant actions to highlight both positive and negative things for the players, as well as important data about their opponents.
It is an excellent tool for learning and improving the technical-tactical elements of the game during training. Therefore, "Data Video" can be used during training periods using a camera, and the images during training can be projected in real time onto a panel, where players and coaches can see previous actions.

Data Video is an excellent help in preparing matches, where the coach gives the players the most relevant information, after analysing in detail all the data. An example of a pre-game video presentation can be the analysis of the opposing team for each part of the game. Here we can track your opponents and their preferences on certain areas and rotations of the field, the positioning of players in the reception, the defence system (blocking - defence) and many other details that can help to make out a tactical game plan (Photo 8). In addition to this, individual video montages can be made on each player with the specific actions of the game station, videos can be made with the distribution of the opposing Setter, video of the movement during blocking of the opposing team, or other options that the coach from the team statistician can request.

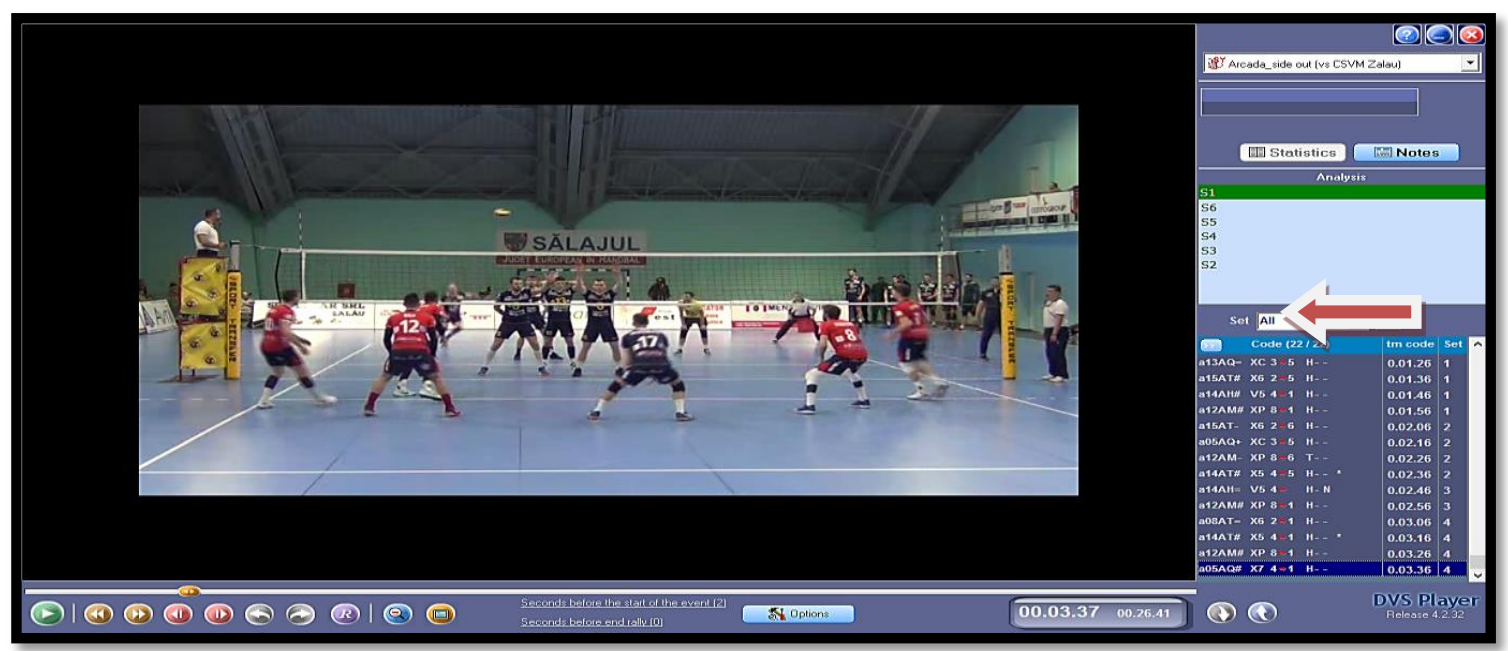

Photo 8. Video montage of technical actions performed according to rotation

The technology evolved so much that this video system can also be used during the game and can provide real-time images of previously completed actions. Therefore, the coach can request a video from the statistician during the game and he can review certain game 
situations that could be very important in the decision-making process during matches. For the most accurate and complete analysis, at the end of the matches, after all video synchronizations are done, an evaluation of all actions taken during the game can be made. In conclusion, coaches who can use such a video system, can greatly accelerate the learning process of players and increase their in-game efficiency if it is used effectively.
In conclusion, we say that better efficiency can be given to coaches who use both the statistics program and the video value system throughout the competition season. Data Volley, can be easily used at any level of volleyball training, regardless of the stage at which it is located. We believe that the use of this program will bring a number of benefits to volleyball specialists and could be extrapolated to other team sports games as well.

\section{References:}

1. Data Project. Data Volley HandBook, Bologna 2007. 104 p. Created and distributed by: DataProject sport software. Disponibil: www.dataproject.com.

2. Data Video Professional HandBook Bologna 2007. Software for the analyses of digital videos of volleyball, basketball and other sports. 63 p. Disponibil: http://datavolley.sstore.pl/download.php?att=1.

3. Mârza D. (2006). Optimizarea și dirijarea pe baze informatice a pregătirii și competiției în jocurile sportive. Iași: Editura, PIM, p. 19-22, p. 49-55, p. 66-88, p. 169.

4. Niculescu I. I. (2006). Volei. Craiova: Editura Universitaria. 120 p.

5. Păcuraru A. (2004). Analiza informaţiei şi procesul de decizie, factori importanţi în randamentul jucătorului de volei. În: Al II-lea Congres Internaţional de educaţie fizica şi sport „Mişcarea-punte de legătură între gândire şi acţiune”. Editura Risoprint, p. 24-28.

6. Pârvu C. (2017). Evaluarea şi corectarea tehnicii la volei prin implementarea aparatelor moderne-ajutătoare. Craiova: Editura Universitaria, p. 9-10.

7. Prescorniță A. (2008). Cartea antrenorului de volei. Brașov: Editura Universității „Transilvania”. $235 \mathrm{p}$.

8. Фурманов А.Г. (2007). Подготовка волейболистов. Минск: МЕТ, с. 245- 330.

9. $\quad$ www.dataproject.com 